\title{
Examining Economic Efficiency of U.S. Government Grading System: The Case of Louisiana Rough Rice
}

\author{
Sung C. No (Corresponding author) \\ Department of Economics and Finance, College of Business \\ Southern University and A\&M College, United States \\ E-mail: sungchno@gmail.com \\ Michael E. Salassi \\ Department of Agricultural Economics and Agribusiness \\ Louisiana State University Agricultural Center, United States \\ E-mail: Msalassi@agcenter.lsu.edu
}

Received: February 23, 2011 Accepted: Mar 21, 2011 doi:10.5430/rwe.v2n1p2

\begin{abstract}
This study estimates a hedonic price model for Louisiana rough rice to evaluate the USDA grading system. The parameter estimates suggest that chalky kernel and red rice are significant quality factors that affect prices in the bid/acceptance regional rough rice market. Results also show that head and broken rice are as important characteristic as the USDA grade quality factors. Generalized least-squares estimation indicates that the USDA grades do not fully explain the observed price variations in Louisiana rough rice. The study constructs a modified grading system for rice. Comparisons show that the modified grading system outperforms the current government grading.
\end{abstract}

Keywords: USDA grading system, Rough rice, Hedonic pricing model, Modified grading

\section{Introduction}

Asymmetric information on product quality is major concern between buyers and sellers in many agricultural product markets. Concern is even greater among agricultural market participants especially who perceive that agricultural commodities are of a heterogeneous nature and exhibit differences in quality, variety, and physical attributes. In fact, to alleviate such asymmetric information problems, federal grading system has been adopted for grains after the 1916 Grain Standards Act was passed in the Congress and thus its success is based on how well it has transmitted relevant information about attributes or characteristics embodied in a commodity to buyers in agricultural markets.

The quality factors selected for U.S. grades in the early 1900s were based on trade practices, not research. Since the inception of the grading system, the U.S. Department of Agricultural (USDA) has made numerous trivial changes in definitions, and factor limits in response to pressure from farmers and importers. However, the quality factors in the grading system have remained virtually unchanged despite major changes in production, marketing, processing, and measurement technology (Hill, 1998).

Several studies have examined whether or not federal grading properly transmits relevant information about attributes or characteristics embodied in a commodity to buyers in agricultural markets. Hill (1998) found that the USDA grading system for grains fails to convey accurate information about end-use grain qualities. An early study by Brorsen, Grant, and Rister (1984) had provided similar evidence for the hypothesis of economic inefficiency in the USDA grading system for rice in Texas. Another study by Espinosa and Goodwin (1991) provided a similar finding on the economic efficiency of the US grading system for wheat. Based on regressions of conventional grading system on quality variables, they argued that the relationship between the grading system and price differences was quite limited.

Despite similar findings of economic inefficiency in the USDA grading system, the earlier studies have made limited constructive recommendation for underperformed USDA grading system for grains. The general purpose of this paper is to examine the economic efficiency of the USDA grading system for rice. More specifically, the study investigates econometrically whether or not the information embodied in Federal grades for rice properly explains the observed price variation. The current study differs from earlier studies in several ways. It uses population data of bid/acceptance market 
transactions in Louisiana. For estimation of empirical models, the study adopts an econometric estimation approach that earlier studies have not considered. Lastly, the paper makes an instructive recommendation for the existing grading system for rice.

A two step approach is used to achieve the general objective. First, the study identifies the quality factors that the current USDA rice grading system does not consider for grade designation, but that are commonly used to gauge rice quality in the market place. Hedonic price functions are applied to these identified factors, along with the factors considered for the USDA rice grading system. Second and more importantly, a set of significant quality variables from the hedonic price function are used to construct a modified grading system for rice. The paper compares and contrasts the performances of economic efficiency in the modified grading system and the current USDA grading system for rice. Finally, the paper summarizes with an instructive recommendation for the current rough rice grades.

\section{Previous Studies}

Several studies have examined quality factors and USDA grading system for different agricultural commodities. Although variables used for analysis were different in the studies, most researchers have used hedonic price models to produce results that were often not in favor of the current USDA grading system. Early research publications dealing with the evaluation of USDA grading system and quality relationships in Louisiana rice prices include the study of Martinez, Traylor, and Fielder (1996) who estimated the effects of quality and non-quality factors on rough rice prices. Using regression analysis, they examined the individual impact each quality factor had on the single numerical grade under federal government grading system. They reported that the only factor that significantly affected price was red rice. Based on these findings, they questioned whether some of the other factors could be combined to facilitate streamlining the USDA grading system.

Based on a linear programming input characteristic model, Ladd and Martin (1976) evaluated the USDA grading system for corn. They showed that the existing corn-grading system could not provide a consistent and optimal sign ranking for corn. They identified an alternative grading system named a non-grading of specified order method, which simply reports all numerical values of quality factors for corn in a specified order.

The other hedonic price study by Brorsen, Grant, and Rister (1981) found the percentage of whole grain rice produced from a given amount of rough rice, reflected in price premiums, to be the most important quality characteristic. Peck was found to be an important rough rice price discount factor. They argued that the USDA grading system for rough rice in Texas inadequately represents the value of rough rice. A study by Hill (1998) provided additional evidence that the grading system for grains was inefficient to convey accurate information about end-use grain qualities. He further argued that it provided producers little incentive for improving grain quality. Motivated by Hill's earlier study, Espinosa and Goodwin (1991) examined the efficiency of the existing federal grading and pricing practice for wheat. They found the relationship between them to be quite limited.

In response to changes in the federal grading system in 1986, designed to incorporate information about end use value, Reimer and Hill (2003) re-evaluated the current federal grading system for corn. They found the inadequacies of current U.S. grades for transmitting adequate information about the evolving quality needs of foreign buyers. They also suggested that easily measured intrinsic quality factors, such as starch, protein, and oil should be incorporated into U.S. corn grades. Excluding the Ladd and Martin (1976) study, none of the previous studies specifically made any instructive recommendation for USDA grading system improvements, although each study examined one or more important aspect of quality factors and federal grades.

\section{Hedonic Price Model}

Louisiana mills purchase rough rice in bid/acceptance markets once the moisture content of rice has been reduced to an appropriate level (i.e., 12\% or 13\%). The milling of rough rice produces milled rice and its byproducts (i.e., bran, and hulls) for marketing to final consumers. Markets for these byproducts are well established. For example, hog producers have used an increasing amount of hulls as feed in their production operations. Beer brewers have increased their purchase of rice brokens over the past years (No, 2001; Reimer and Hill, 2003).

Drawing on the neoclassical input characteristics model constructed by Ladd and Martin [8], this study considers a representative profit maximizing rice miller in a competitive market, subject to an input characteristics production function. In other words, the production function for a representative miller can be represented as:

$$
Y_{k}=F_{k}\left(Z_{1 k}, Z_{2 k}, \ldots, Z_{m k}\right) \text {, }
$$


where $Y_{k}$ is the quantity of output $k$ (i.e., milled rice) and $Z_{m k}$ is the total quantity of grain characteristic $m(m=1, \ldots, M)$. Equation (1) indicates that the amount of milled rice depends on peck, chalky kernel, brokens, red rice, and foreign seeds. Then, a profit maximizing miller's profit $(\Pi)$ function can be written as

$$
\Pi=\sum_{i=1}^{I} P_{i} F_{i}\left(Z_{1 i}, \cdots, Z_{m i}\right)-\sum_{i=1}^{I} \sum_{j=1}^{J} L_{j} X_{i j},
$$

where $P_{i}$ are output prices for milled head rice, bran, millfeed, brokens, and hulls, $L_{j}$ is the price paid for the $j$ th input, and $\mathrm{X}_{i j}$ is the quantity of the $j$ th input used in the production of $i$ th output product. Now differentiate the profit function with respect to $X_{i j}$. Using a chain rule (Note 1), equation (2) yields:

Solving for $L_{j}$,

$$
\partial \Pi / \partial X_{i j}=P_{i} \sum_{i=1}^{I}\left(\partial F_{i} / \partial Z_{m i}\right)\left(\partial Z_{m i} / \partial X_{i j}\right)-L_{j}=0
$$

$$
L_{j}=P_{i} \sum_{i=1}^{I}\left(\partial F_{i} / \partial Z_{m i}\right)\left(\partial Z_{m i} / \partial X_{i j}\right),
$$

where $\partial Z_{m i} / \partial X_{i j}$ is the marginal yield of characteristic $m$ in the production of $i$ th output from $j$ th input, $\partial F_{i} / \partial Z_{m j}$ is the marginal physical product from one unit of characteristic $m$ used in production of the $j$ th input product, and $P_{i} \partial F_{i} / \partial Z_{m i}$ is the value of the marginal product of the $m$ th characteristic used in production of output $i$. Equation (4) indicates that the price paid for rough rice equals the sum of marginal implicit prices of the characteristics embodied in rough rice multiplied by the marginal yield of those characteristics. By assuming that $P_{i} \partial F_{i} / \partial Z_{m i}=H_{m i}$ and $\partial Z_{m i} / \partial X_{i j}=Z_{m i j}$ are both constant (Note 2), Equation (4) can be simplified as a linear hedonic price function:

$$
L_{j}=\sum_{m=1}^{M} H_{m i} Z_{m i j},
$$

where $H_{m i}$ is the marginal implicit value of the characteristic $m$ and $Z_{m i j}$ is the quantity of characteristic $m$ contained in each unit of input $j$ that goes into the output production of $i$. By regressing input prices on input characteristics, as measured by the $Z_{m i j}$, one can determine the effect that physical characteristics have on the prices paid for rough rice and thus measure the marginal implicit values of characteristics (i.e., brokens, red rice, peck, chalky kernel, and others). This hedonic price function is used for empirical estimation below.

\section{Empirical Model}

Millers in Louisiana participate in closed and sealed markets to buy rough rice to process for final consumers. Millers consider several factors when they make purchasing decision on a particular lot of rice. These factors are included in the hedonic price function below:

$$
F P=\mathrm{f}(H E A D, B R O K E N S, C H A L K, \text { PECK, RED }),
$$

where $F P$ is rough rice price, $H E A D$ is head rice in $\%$ by weight of three-fourths or greater whole kernels in the sample, $B R O K E N S$ are broken rice in \% by weight of less than three-fourths of whole kernels, CHALK is chalky kernel in \% by weight of whole kernels one-half or more chalky, PECK is measured in \% by weight of kernels damaged by stink bugs, and $R E D$ is red rice in \% by weight of whole or broken kernels on which there is an appreciable amount of red bran.

Head rice is the most important factor used to measure end-use performance of rice for foods. Percentage of head rice is used to predict the quantity of milled rice. Head rice is thus a desirable component of rice and is expected to exhibit a positive influence on rough rice price. Brokens are kernels of rice that are less than three-fourths of the length of the whole kernels. Food processors purchase brokens for use in food products, such as beer, cereal, soups, and pet foods. As such, brokens are expected to have a positive influence on rice price. But they are not as desirable as head rice.

Chalky kernel of undeveloped or immature areas indicates a "chalky" appearance in rice and usually reduces milling yield. Therefore, there expected to be a direct discount due to chalky kernel. Peck is an important characteristic in that higher stink bug-damaged kernels substantially reduce the milling yield. As a result, peck is expected to have a negative effect on rice prices. Red rice is a common weed problem in rice fields in the southern United Sates that can significantly reduce rice yields and quality for foods. Thus, it is expected to lower the prices received for rice.

\section{Data}

Sealed bid auction data for the marketing years 1994/95 and 1998/99 were obtained from the Louisiana Farm Bureau Marketing Association's office in Crowley. The sealed bid auction data included comprehensive transaction records: sales date, lot number, bin number, approximate location, variety, lot size in hundredweight, Government grade levels, and estimated loan deficiency payment. The data also included milling characteristics, such as head, total milling yield, other quality characteristics including the percentage of red rice, chalk kernel, and peck in rough rice. In addition, the sales sheet data contained bid prices of all buyers who chose to bid on that particular lot, loan value, and disposition, indicating if highest bid was accepted or rejected. Since rejected offer prices do not represent the market equilibrium price, only accepted final settlement prices were used for the current study. The most recent and reliable data for the 
current study were for the marketing year 1998/99 because the Louisiana data collection agency discounted data filing due to its budget constraints.

\section{Empirical Results}

The model was first estimated for each year as well as two years combined. The Chow test results (Intriligator, Bodkin, and Hsiao, 1996) indicated that the estimation from pooled data for the marketing years 1994/95 and 1998/99 was not appropriate. Therefore, the pooled estimation is not reported. Although the data set did not constitute a true times-series, autocorrelation problems were expected because the observations were arranged in time sequence in the data set. First, the ordinary least squares procedure was used to verify whether or not the expected autocorrelation was present (i.e., via inspections of Durbin-Watson statistic). Then, generalized least squares procedure was used to estimate the proposed models.

The numbers of the final settlement prices for the marketing years 1994/95 and 1998/99 were 478 and 426, respectively. Average accepted bid price was $\$ 6.23 / \mathrm{cwt}$ in 1994 and $\$ 8.02 / \mathrm{cwt}$ in 1998 . This price differential is attributed to major aggregate supply and demand shifters in rice market. Extreme values for the marketing year 1994/95 were $\$ 1.96 / \mathrm{cwt}$ at a minimum and $\$ 8.33 / \mathrm{cwt}$ at the maximum; for the marketing year $1998 / 1999, \$ 4.05 / \mathrm{cwt}$ at a minimum and $\$ 10.21 / \mathrm{cwt}$ at the maximum.

The Federal Grain Inspection Services sets quality characteristics and their maximum limits for the classes of rough rice. Prior to market day in a bid/acceptance market, qualified graders estimate the amount of weed seeds, damage, red rice, chalkiness, general appearance, and "other quality factors" and assign a numeric grade 1 being the highest grade and 7 being the most inferior grade to each lot of rough rice.

More specifically, based on the maximum limits for each of the quality factors, qualified graders assign a numeric grade to a sample of rice according to "worst factor rule". For instance, if a sample of rice has a grade designation of 1 in all quality factors except one factor with a grade designation of 3, the final grade for inspected rice will be grade level of 3. For chalky kernel, the maximum allowable amount is no greater than $1 \%$ in long grain rice to be qualified for USDA Grade 1; $2 \%$ for Grade 2; $4 \%$ for Grade 3; $6 \%$ for Grade 4; $10 \%$ for Grade 5; and 15\% for Grade 6 . Over 15\% of chalky kernel in rice is rated as Grade 7. The study computed an average prices corresponding to the maximum limits of chalky kernel set by the USDA Rice Grading System. Results are summarized in Table 1.

$<$ Table 1 about here $>$

It can be noted that prices generally decreased as the amount of chalky kennels contained increases. For instance, average price for medium grain rice rated at level 1 was much higher than rated at level 6 . However, there were several exceptions to this pattern. Average price of medium grain rice rated at level 3 in marketing year 1994/95 was lower than average price for the subsequent grade level. Average price of long grain rice rated at level 4 in marketing year 1994/95 was lower than average price for inferior grade levels. For marketing year 1998/99, the general inverse relationship between the grade level and rice prices were observed.

With respect to red rice, Table 2 shows no general patterns between the quality factor and average rice prices. The highest average price for medium rice in marketing year 1994/95 occurred at relatively inferior grade level of 5. Similarly, average price of long grain rice rated at level 1 was much lower than the sample price of rice at level 4 in marketing year 1994/95. Thus, it was suggested that the USDA grade designation based on red rice contents does not properly explain the price movements.

\section{$<$ Table 2 about here $>$}

To examine whether or not Federal grades, in general, conform to price differentials, the study computed average prices for different grades set by the government. The results are reported in Table 3. Prices generally decreased as the grade scale increases. However, there were a few exceptions to this inverse relationship. For instance, average price for medium grain rice graded No. 1 was much lower than that graded No. 2 for marketing year 1994/95. Other inconsistency of grades with prices existed for medium rice graded No.5 and No. 6. Given a fairly small number of observations, this nonconformity of prices with grades might be outliers rather than routines. But that was not the case for long grain rice graded No. 2 and No. 3 and No. 5 and No. 6 with observations of 316 and 51, respectively. This might be indicative of inconsistent association of federal grades with price differentials.

\section{$<$ Table 3 about here $>$}

The study performed multiple regression analyses to further examine whether or not the information conveyed by the USDA grades (hereafter, the USDA grade model) can better explain the observed price variation than quality 
characteristics incorporated in the hedonic price function (hereafter, hedonic price model). Regression equation for the USDA grade model is specified as follows:

$$
F P_{t}=b_{10}+b_{11} G_{1 t}+b_{12} G_{2 t}+b_{13} G_{3 t}+b_{14} G_{4 t}+b_{15} G_{5 t}+u_{t},
$$

where $G_{i t}, \quad i=1, \ldots, 5$ are government grade dummy variables.

The hedonic price model for rough rice is written as:

$$
F P_{t}=b_{20}+b_{21} \text { HEAD }_{t}+b_{22} \text { BROKENS }_{t}+b_{23} \text { PECK }_{t}+b_{24} R E D_{t}+b_{25} C H A L K t+v_{t}
$$

where all variables in the hedonic model are continuous variables in levels; $b_{i j}$ are $i=1$ and 2 and $j=1, . ., 5$ are coefficients to be estimated; and $\mathrm{u}_{\mathrm{t}}$ and $\mathrm{v}_{\mathrm{t}}$ are disturbance terms. Lower Durbin-Watson statistic from ordinary least square estimation lead to a formal test for autocorrelation. The Godfrey test (Godfrey, 1978) ensured the use of generalized least squares for appropriate analysis.

Table 4 presents the significance of quality characteristics and dummy grade variables for marketing year 1994/95. As for the USDA grade model, all generalized least square estimates were consistent with the hypothesis that better graded rice is selling with premiums (i.e., to avoid muliticollinearity problem, Grade 6 was dropped. Thus, all signs of dummy coefficient estimates are expected to be positive). Estimates of the hedonic price model were consistent with a priori expectations. One exception was an unexpected positive sign on RED. However, the parameter estimate was not much different from zero $(t$-value $=1.27)$.

Adjusted $\mathrm{R}^{2}$ values of 0.83 and 0.64 for marketing year 1994/95 associated with the hedonic model for long and medium grain rice, respectively suggest that five quality factors together offered a more powerful explanation of observed price variation than Government dummy variables combined (i.e., merely 0.16 and 0.17 for marketing year 1994/95 and 1998/99, respectively). This might be indicative of insufficient representation of the USDA grade model for rough rice. In addition, Akaike Information Criterion (1981) suggests that the hedonic price models are better in comparison to government grade models for long and medium grain, because smaller Akaike Information Criterion (AIC) numbers are found in the hedonic price.

$<$ Table 4 about here $>$

Table 5 shows that for marketing year 1998/99 generalized least square estimates for hedonic price model are consistent signs with a priori expectations. Those estimates were significant at the $5 \%$ level of significance with two exceptions. Unlike Brorsen, Grant, and Rister (1984) suggested for their study for rice in Texas, Peck is found to be an inadequate representation of the value of rice price for the sample period. Comparison of the coefficient determinations suggests that the information conveyed by four quality factors can better explain the observed price variation than the USDA model for long grain rice.

$<$ Table 5 about here $>$

\section{Modified Grading System (Note 3)}

The hedonic price model above indicated that HEAD, BROKENS, RED, and CHALK have a significant impact on prices by buyers in Louisiana bid/acceptance markets. Using these quality characteristics, the study proposes a modified grading system, especially for Louisiana rough rice to provide a constructive recommendation. In other words, we modify the current USDA grading system, by adding easily measurable HEAD/TOTAL milling yield to the existing quality factors, such as RED and CHALKY kernel.

Notice that we choose grades criteria for HEAD and TOTAL milling yield instead of HEAD and BROKENS. TOTAL milling yield is substituted for the variable of $B R O K E N S$ because most of rice trade in futures market and international markets quote transactions using HEAD/TOTAL milling yield. Despite this replacement, there should not be loss of general observations made earlier in that the variable of BROKENS is identical to the TOTAL milling yield minus HEAD rice yield.

Observations of both international and futures markets for rice are greatly useful in obtaining minimum limits of HEAD/TOTAL milling yield in rough rice for different grade levels. Rice trades for 5\% BROKENS (or TOTAL minus $H E A D$ ) have been existed in the international market for extended period time. In futures markets, standardized rice deliverable grade is long grain rough rice with a total milling yield of not less than $65 \%$ including head rice of not less than $48 \%$. Premium and discounts are provided for each $\%$ of head rice. In addition, standardized cash price for 55/70 is available to traders (Giesler, Gautier, and Salassi, 1998).

Accordingly, the following grade designations seem appropriate for HEAD/TOTAL milling yield in rice: 65/70, 55/70, $55 / 60,48 / 65,48 / 55$, and 30/30 for Grade level 1 through 6, respectively. For instance, a total milling yield of not less 
than $70 \%$ including head rice of no less than $65 \%$ in rice sample should be rated Grade 1 in modified grading system. We keep maximum limits of RED and CHALKY kernel set by the Federal Grain Inspection Service for modified grading system. Complete grading specification is summarized in Table 6 .

\section{$<$ Table 6 about here $>$}

Table 7 shows the average price for different grades rated by the USDA grading system and modified grading system. A comparison of these two grading system reveals that average prices for modified grades are higher than those for federal grades except for Grade 6. More importantly, price discrepancies occur at lower and higher grades in the USDA grading system could not be found in the modified grading system.

\section{$<$ Table 7 about here $>$}

The explanatory power of the modified grade model for the marketing year 1994/95 is much greater than that of the USDA grade model as indicated by the model's distinctly superior statistics, such as higher $\mathrm{R}^{2}$ and statistical significance of estimated coefficients. Table 8 shows that the modified grade model explains $66 \%$ of the variation in rough rice prices, while the USDA grade model accounts only for $16 \%$ of the price variation. In addition, much smaller AIC number in the modified grade model indicates that the USDA grade model is an inferior model specification for rough rice.

$<$ Table 8 about here $>$

Table 9 presents a similar result for the marketing year 1998/99 that the USDA grade model poorly explains the price variations of rough rice; on the other hand, the explanatory power of the modified grade model is almost four times higher than that of the USDA grade model. This result strongly suggests that a grading efficiency might be greatly improved if additional quality factors are incorporated into the existing system. In other words, we expect that inclusion of HEAD and TOTAL milling yields might considerably enhance performance of grading system in a market place, especially in Louisiana rough rice market.

$<$ Table 9 about here $>$

\section{Summary and Recommendations}

In response to non-instructive reports on the economic efficiency of USDA grading system for grains, this study has investigated econometrically how well USDA rough rice grades explain the observed price variations in Louisiana rough rice. A hedonic price model was specified and estimated using a generalized least square estimator because of severe autocorrelations in errors.

Several observations emerged from the empirical results. First, chalky kernel and red rice are significant quality factors that affect prices in the bid/acceptance regional rough rice market. Head and broken rice that the Federal agency has not incorporated into grading are as important characteristic as the other quality factors.

Second, descriptive statistics of average prices for different grades set by the USDA grades revealed that there was inconsistency of grades with price, especially in long grain rough rice. Additional results from generalized least estimates indicated that the USDA rough rice grades do not adequately explain the observed price variations in Louisiana rough rice.

Lastly, given these observations, the paper formed a modified grading system for rice in accordance with the findings of hedonic price functions. Comparison of the two grading system showed that the modified grading system greatly outperforms the current government grading in terms of explanatory power of price variations in the regional rough rice. Therefore, it is possible to greatly improve the underperformed current federal grading system by incorporating easily measurable head/total milling yield into the grading system with grade standards specified in this study.

Although these findings on the economic efficiency of the USDA grading system were obtained from Louisiana, similar results are expected to hold in other rice producing markets, given extremely high price correlations among these markets. It is very likely that the current proposal requires costs of implementation by the federal agent. However, economic costs may not be major, given the fact that most of the rice producing states, such as Louisiana and Texas have already made the information on head/total milling yield in rice available to participants in bid/acceptance markets. 


\section{References}

Akaike, H (1981). Likelihood of a Model and Information Criteria. Journal of Econometrics 16, 3-14. doi:10.1016/0304-4076(81)90071-3, http://dx.doi.org/10.1016/0304-4076(81)90071-3

Brorsen, B. W, Warren R. G. \& Rister, Edward. (1984). A Hedonic Price Model for Rough Rice Bid/Acceptance Markets. American Journal of Agricultural Economics 66, 156-163. doi:10.2307/1241032, http://dx.doi.org/10.2307/1241032

Espinosa, Juan A. \& Goodwin, Barry K. (1991). Hedonic Price Estimation for Kansas Wheat Characteristics. Western Journal of Agricultural Economics 16, 72-85.

Giesler, G. Grant, Gauthier, Wayne M. \& Salassi, Michael E. (1998). An Estimation of Rough Rice Basis in Southwest Louisiana. Technical Bulletin No. 865, Louisiana State University Agricultural Center, Department of Agricultural Economics and Agribusiness, Louisiana State University, Baton Rouge.

Godfrey, L (1978). Testing for Higher Order Serial Correlation in Regression Equations When the Regressors Include Lagged Dependent Variables Econometrica, 46, 1303-1310.

Hill, L.D (1998). Grain Grades: They Lack Economic Rationale. Choices 1, 24-27.

Intriligator, Michael D., Bodkin, Ronald G. \& Hsiao, Cheng (1996). Econometric Models, Techniques, and Applications. Upper Saddle River: Prentice Hall.

Ladd, George W. \& Martin, Marvin B. (1976). Prices and Demands for Input Characteristics. American Journal of Agricultural Economics 58, 21-30. doi:10.2307/1238573, http://dx.doi.org/10.2307/1238573

No, Sung C (2001). A Dynamic Economic Model for the U.S. Rice Market. Unpublished Ph.D. dissertation, Department ofAgricultural and Agribusiness, Louisiana State University, Baton Rouge.

Martinez, Adolfo, Traylor, Harlon D. \& Fielder, Lonnie L. Jr. (1976). Analysis of Effects of Quality and Non-Quality Factors on Prices of Medium and Long Grain Rough Rice in Louisiana. D.A.E. Research Report No. 507, Department of Agricultural Economics and Agribusiness, Louisiana Agricultural Experiment Station, Louisiana State University, Baton Rouge.

Reimer, Jeffrey J. \& Hill, Lowell D. (2003). Designing U.S. Corn Grades to Reflect End Use Value. Journal of Agricultural and Applied Economics, 35,15-28.

Setia, Parveen, Childs, Nathan, Wailes, Eric \& Livezey, Janet (1994). The U.S. Rice Industry. Agricultural Economic Report Number 700, USDA, Economic Research Service. Washington, DC.

United States Department of Agriculture (2002). United States Standards for Rice. Grain Inspection, Packers, and Stockyards Administration, Federal Grain Inspection Service, Washington D.C.

\section{Notes}

Note 1. A chain rule is used because $F_{i}$ is a function of the $Z_{m i}$ and $Z_{m i}$ is functions of the $X_{i j}$.

Note 2. For further justification of this simplifying assumption, refer to Espinosa and Goodwin.

Note 3. Although the estimates results for medium rice are presented for marketing year 1998/99, they are inefficient estimates due to small sample sizes. The study hardly draws on those estimates for meaningful implications. Therefore, the following analysis is confined to long grain rice. 
Table 1. Average Rough Rice Prices Corresponding to the Maximum Limits of Chalky Kernels Set by the USDA Rice Grading System for 1994/95 and 1998/99

\begin{tabular}{|c|c|c|c|c|}
\hline \multicolumn{5}{|c|}{ Chalky Kernels (percent) for 1994/95 } \\
\hline Grade & Medium & Avg. Prices & Long & Avg. Prices \\
\hline US No. 1 & 2.0 & 7.56 & 1.0 & 6.46 \\
\hline US No. 2 & 4.0 & 6.35 & 2.0 & 6.43 \\
\hline US No. 3 & 6.0 & 5.99 & 4.0 & 5.89 \\
\hline US No. 4 & 8.0 & 6.17 & 6.0 & 4.56 \\
\hline US No. 5 & 10.0 & 6.00 & 10.0 & 4.76 \\
\hline US No. 6 & 15.0 & na & 15.0 & 7.06 \\
\hline \multicolumn{5}{|c|}{ Chalky Kernels (percent) for 1998/99 } \\
\hline Grade & Medium & Avg. Prices & Long & Avg. Prices \\
\hline US No. 1 & 2.0 & na & 1.0 & 8.47 \\
\hline US No. 2 & 4.0 & 9.23 & 2.0 & 8.01 \\
\hline US No. 3 & 6.0 & 8.15 & 4.0 & 7.72 \\
\hline US No. 4 & 8.0 & 7.54 & 6.0 & 5.07 \\
\hline US No. 5 & 10.0 & na & 10.0 & na \\
\hline US No. 6 & 15.0 & na & 15.0 & na \\
\hline
\end{tabular}

Table 2. Average Rough Rice Prices Corresponding to the Maximum Limits of Red Rice Set by the USDA Rice Grading System for 1994/95 and 1998/99

\begin{tabular}{|c|c|c|c|c|}
\hline \multicolumn{5}{|c|}{ Red Rice (percent) for 1994/95 } \\
\hline Grade & Medium & Avg. Prices & Long & Avg. Prices \\
\hline US No. 1 & 0.5 & 6.34 & 0.5 & 5.60 \\
\hline US No. 2 & 1.5 & 6.06 & 1.5 & 6.14 \\
\hline US No. 3 & 2.5 & 6.12 & 2.5 & 6.20 \\
\hline US No. 4 & 4.0 & 6.42 & 4.0 & 6.32 \\
\hline US No. 5 & 6.0 & 6.70 & 6.0 & 5.68 \\
\hline US No. 6 & 15.0 & 6.27 & 5.0 & 5.25 \\
\hline \multicolumn{5}{|c|}{ Red Rice (percent) for 1998/99 } \\
\hline Grade & Medium & Avg. Prices & Long & Avg. Prices \\
\hline US No. 1 & 0.5 & 8.81 & 0.5 & 7.92 \\
\hline US No. 2 & 1.5 & 8.52 & 1.5 & 8.05 \\
\hline US No. 3 & 2.5 & 8.39 & 2.5 & 8.05 \\
\hline US No. 4 & 4.0 & 6.86 & 4.0 & 7.94 \\
\hline US No. 5 & 6.0 & 9.04 & 6.0 & 8.30 \\
\hline US No. 6 & 15.0 & na & 15.0 & 7.75 \\
\hline
\end{tabular}


Table 3. Average Rough Rice Prices by the USDA Rice Grading System for 1994/95 and 1998/99

\begin{tabular}{|c|c|c|c|c|}
\hline \multicolumn{5}{|c|}{ Marketing Year 1994/95 } \\
\hline Grade & Observation & Medium Prices & Observation & Long Prices \\
\hline US No. 1 & 1 & 5.72 & 13 & 7.00 \\
\hline US No. 2 & 17 & 6.55 & 243 & 6.38 \\
\hline US No. 3 & 21 & 6.45 & 53 & 6.13 \\
\hline US No. 4 & 28 & 6.17 & 44 & 5.79 \\
\hline US No. 5 & 18 & 5.94 & 15 & 5.61 \\
\hline US No. 6 & 12 & 5.79 & 13 & 5.32 \\
\hline \multicolumn{7}{|c|}{ Marketing Year 1998/99 } \\
\hline Grade & Observation & Medium Prices & Observation & Long Prices \\
\hline US No. 1 & 0 & na & 1 & 8.50 \\
\hline US No. 2 & 1 & 9.45 & 231 & 8.14 \\
\hline US No. 3 & 7 & 9.07 & 85 & 7.95 \\
\hline US No. 4 & 4 & 8.15 & 57 & 8.14 \\
\hline US No. 5 & 3 & 7.66 & 32 & 7.22 \\
\hline US No. 6 & 2 & 8.68 & 19 & 7.75 \\
\hline
\end{tabular}

Table 4. GLS Estimations of the Government Grade model and Hedonic Model for Louisiana Rouge Rice Prices for a marketing year 1994/95

\begin{tabular}{|c|c|c|c|c|}
\hline & \multicolumn{2}{|c|}{ Hedonic Model } & \multirow{2}{*}{\multicolumn{2}{|c|}{$\begin{array}{c}\text { Government Grade Model } \\
\text { Dependent Variable }\end{array}$}} \\
\hline \multirow{2}{*}{$\begin{array}{c}\text { Independent } \\
\text { Variable }\end{array}$} & \multicolumn{2}{|c|}{ Dependent Variable } & & \\
\hline & Long Grain & Medium Grain & Long Grain & Medium Grain \\
\hline \multirow[t]{2}{*}{ Intercept } & $-0.791^{* *}$ & -1.467 & $5.346^{* *}$ & $5.788^{* *}$ \\
\hline & $(-2.01)$ & $(-1.19)$ & $(28.91)$ & $(31.24)$ \\
\hline \multirow[t]{2}{*}{ G1 } & & & $1.551^{* *}$ & 0.073 \\
\hline & & & $(5.77)$ & $(0.11)$ \\
\hline \multirow[t]{2}{*}{ G3 } & & & $0.513^{* *}$ & $0.376^{* *}$ \\
\hline & & & $(5.53)$ & $(3.18)$ \\
\hline \multirow[t]{2}{*}{ G4 } & & & $0.248^{* *}$ & $0.228^{* *}$ \\
\hline & & & $(3.67)$ & $(3.02)$ \\
\hline \multirow[t]{2}{*}{ G5 } & & & $0.125^{* *}$ & 0.098 \\
\hline & & & $(2.46)$ & $(1.79)$ \\
\hline \multirow[t]{2}{*}{ G6 } & & & 0.064 & 0.021 \\
\hline & & & $(1.34)$ & $(0.46)$ \\
\hline \multirow[t]{2}{*}{ Head } & $0.118^{* *}$ & $0.124^{* *}$ & & \\
\hline & $(21.87)$ & $(7.25)$ & & \\
\hline \multirow[t]{2}{*}{ Brokens } & $0.056^{* *}$ & $0.060^{* *}$ & & \\
\hline & $(7.21)$ & $(2.47)$ & & \\
\hline \multirow[t]{2}{*}{ Peck } & -0.020 & $-0.067^{* *}$ & & \\
\hline & $(-0.96)$ & $(-3.48)$ & & \\
\hline \multirow[t]{2}{*}{ Red } & $-0.089^{* *}$ & 0.063 & & \\
\hline & $(-6.57)$ & $(1.27)$ & & \\
\hline \multirow[t]{2}{*}{ Chalk } & $-0.044^{* *}$ & -0.028 & & \\
\hline & $(-2.49)$ & $(-0.64)$ & & \\
\hline $\mathrm{R}^{2}$ & 0.83 & 0.64 & 0.16 & 0.17 \\
\hline DW & 2.26 & 1.89 & 2.11 & 1.97 \\
\hline $\mathrm{T}$ & 381 & 97 & 381 & 97 \\
\hline AIC & 204 & 112 & 791 & 190 \\
\hline
\end{tabular}

Notes: Asterisks, ** indicates statistical significance at the 5\% level or better, two-tailed test. 
Table 5. GLS Estimations of the Government Grade model and Hedonic Model for Louisiana Rouge Rice Prices for a marketing year 1998/99

\begin{tabular}{|c|c|c|c|c|}
\hline \multirow{3}{*}{$\begin{array}{c}\text { Independent } \\
\text { Variable }\end{array}$} & \multicolumn{2}{|c|}{ Hedonic Model } & \multirow{2}{*}{\multicolumn{2}{|c|}{$\begin{array}{c}\text { Government Grade Model } \\
\text { Dependent Variable }\end{array}$}} \\
\hline & \multicolumn{2}{|c|}{ Dependent Variable } & & \\
\hline & Long Grain & Medium Grain & Long Grain & Medium Grain \\
\hline \multirow[t]{2}{*}{ Intercept } & $-1.224^{* *}$ & 1.628 & $7.512^{* *}$ & $8.423^{* *}$ \\
\hline & $(-3.18)$ & $(0.08)$ & $(39.06)$ & $(9.29)$ \\
\hline \multirow[t]{2}{*}{ G1 } & & & $0.874^{* *}$ & \multirow[t]{2}{*}{ n.a. } \\
\hline & & & $(2.41)$ & \\
\hline \multirow[t]{2}{*}{ G3 } & & & $0.324^{* *}$ & 0.372 \\
\hline & & & $(5.33)$ & $(0.49)$ \\
\hline \multirow[t]{2}{*}{ G4 } & & & $0.134^{* *}$ & 0.254 \\
\hline & & & $(3.22)$ & $(0.76)$ \\
\hline \multirow[t]{2}{*}{ G5 } & & & $0.097^{* *}$ & -0.045 \\
\hline & & & $(3.02)$ & $(-0.17)$ \\
\hline \multirow[t]{2}{*}{ G6 } & & & -0.004 & -0.184 \\
\hline & & & $(-0.13)$ & $(-0.90)$ \\
\hline \multirow[t]{2}{*}{ Head } & $0.146^{* *}$ & 0.117 & & \\
\hline & $(28.80)$ & $(0.45)$ & & \\
\hline \multirow[t]{2}{*}{ Brokens } & $0.106^{* *}$ & 0.111 & & \\
\hline & $(14.88)$ & $(0.38)$ & & \\
\hline \multirow[t]{2}{*}{ Peck } & -0.001 & -0.115 & & \\
\hline & $(-0.03)$ & $(-0.15)$ & & \\
\hline \multirow[t]{2}{*}{ Red } & $-0.036^{* *}$ & 0.025 & & \\
\hline & $(-4.48)$ & $(0.14)$ & & \\
\hline \multirow[t]{2}{*}{ Chalk } & -0.017 & -0.379 & & \\
\hline & $(-0.82)$ & $(-1.15)$ & & \\
\hline $\mathrm{R}^{2}$ & 0.81 & 0.38 & 0.14 & 0.30 \\
\hline DW & 2.46 & 1.62 & 2.36 & 1.79 \\
\hline $\mathrm{T}$ & 426 & 17 & 426 & 19 \\
\hline AIC & 183 & 61 & 813 & 61 \\
\hline
\end{tabular}

Notes: Asterisks, ** indicates statistical significance at the $5 \%$ level or better, two-tailed test.

Table 6. Maximum Limits for Chalky Kernel and Red Rice for Modified Grades for Rouge Rice

\begin{tabular}{|c|c|c|c|}
\hline Grade & Head/Total & Chalky Kernel (percent) & Red rice (percent) \\
\hline No. 1 & $65 / 70$ & 1.0 & 0.5 \\
\hline No. 2 & $55 / 70$ & 2.0 & 1.5 \\
\hline No. 3 & $55 / 60$ & 4.0 & 2.5 \\
\hline No. 4 & $48 / 65$ & 6.0 & 4.0 \\
\hline No. 5 & $48 / 55$ & 10.0 & 6.0 \\
\hline No. 6 & $30 / 30$ & 15.0 & 15.0 \\
\hline
\end{tabular}


Table 7. Average Rough Rice Prices for Different Grades by the USDA Grading System and Modified Grading System for 1994/95 and 1998/99

\begin{tabular}{|c|c|c|c|}
\hline \multicolumn{5}{|c|}{ Marketing Year 1994/95 } \\
\hline Grade & Long Prices & Modified Grade & Long Prices \\
\hline US No. 1 & 7.00 & MG No. 1 & 7.26 \\
\hline US No. 2 & 6.38 & MG No. 2 & 6.86 \\
\hline US No. 3 & 6.13 & MG No. 3 & 6.55 \\
\hline US No. 4 & 5.79 & MG No. 4 & 6.06 \\
\hline US No. 5 & 5.61 & MG No. 5 & 5.85 \\
\hline US No. 6 & 5.32 & MG No. 6 & 5.15 \\
\hline \multicolumn{4}{|c|}{ Marketing Year 1998/99 } \\
\hline Grade & Long Prices & Modified Grade & Long Prices \\
\hline US No. 1 & 8.50 & MG No. 1 & 9.70 \\
\hline US No. 2 & 8.14 & MG No. 2 & 8.28 \\
\hline US No. 3 & 7.95 & MG No. 3 & 8.27 \\
\hline US No. 4 & 8.14 & MG No. 4 & 8.20 \\
\hline US No. 5 & 7.22 & MG No. 5 & 7.63 \\
\hline US No. 6 & 7.75 & MG No. 6 & 7.32 \\
\hline
\end{tabular}

Table 8. GLS Estimations of the Government Grade model and Hedonic Model for Louisiana Rouge Rice Prices for a marketing year 1994/95

\begin{tabular}{|c|c|c|c|}
\hline \multicolumn{4}{|c|}{\begin{tabular}{|l|l|} 
Government Grade Model & Modified Grade Model \\
\end{tabular}} \\
\hline $\begin{array}{l}\text { Independent } \\
\text { Variable }\end{array}$ & $\begin{array}{l}\text { Dependent Variable } \\
\text { Long Grain }\end{array}$ & $\begin{array}{l}\text { Independent } \\
\text { Variable }\end{array}$ & $\begin{array}{l}\text { Dependent Variable } \\
\text { Long Grain }\end{array}$ \\
\hline \multirow[t]{2}{*}{ Intercept } & $5.346^{* *}$ & \multirow[t]{2}{*}{ Intercept } & $5.144^{* *}$ \\
\hline & $(28.91)$ & & $(82.71)$ \\
\hline \multirow[t]{2}{*}{ G1 } & $1.551^{* *}$ & \multirow[t]{2}{*}{ MG1 } & $1.953^{* *}$ \\
\hline & $(5.77)$ & & $(13.07)$ \\
\hline \multirow[t]{2}{*}{ G2 } & $0.513^{* *}$ & \multirow[t]{2}{*}{ MG2 } & $0.867^{* *}$ \\
\hline & (5.53) & & $(23.28)$ \\
\hline \multirow[t]{2}{*}{ G3 } & $0.248^{* *}$ & \multirow[t]{2}{*}{ MG3 } & $0.465^{* *}$ \\
\hline & $(3.67)$ & & $(22.64)$ \\
\hline \multirow[t]{2}{*}{ G4 } & $0.125^{* *}$ & \multirow[t]{2}{*}{ MG4 } & $0.230^{* *}$ \\
\hline & $(2.46)$ & & $(12.64)$ \\
\hline \multirow[t]{2}{*}{ G5 } & $0.064^{* *}$ & \multirow[t]{2}{*}{ MG5 } & $0.141^{* *}$ \\
\hline & $(1.34)$ & & $(7.96)$ \\
\hline $\mathrm{R}^{2}$ & 0.16 & & 0.66 \\
\hline DW & 2.11 & & 2.16 \\
\hline $\mathrm{T}$ & 381 & & 381 \\
\hline AIC & 791 & & 452 \\
\hline
\end{tabular}

Notes: Asterisks, $* *$ indicates statistical significance at the $5 \%$ level or better, two-tailed test. 
Table 9. GLS Estimations of the Government Grade model and Hedonic Model for Louisiana Rouge Rice Prices for a marketing year 1998/99

\begin{tabular}{|c|c|c|c|}
\hline & \multicolumn{2}{|c|}{ Government Grade Model } & Modified Grade Model \\
\hline $\begin{array}{l}\text { Independent } \\
\text { Variable }\end{array}$ & $\begin{array}{l}\text { Dependent Variable } \\
\text { Long Grain }\end{array}$ & $\begin{array}{l}\text { Independent } \\
\text { Variable }\end{array}$ & $\begin{array}{l}\text { Dependent Variable } \\
\text { Long Grain }\end{array}$ \\
\hline \multirow[t]{2}{*}{ Intercept } & $7.512^{* *}$ & \multirow[t]{2}{*}{ Intercept } & $7.232^{* *}$ \\
\hline & $(39.06)$ & & $(38.27)$ \\
\hline \multirow[t]{2}{*}{ G1 } & $0.874^{* *}$ & \multirow[t]{2}{*}{ MG1 } & $1.764^{* *}$ \\
\hline & $(2.41)$ & & $(8.75)$ \\
\hline \multirow[t]{2}{*}{$\mathrm{G} 2$} & $0.324^{* *}$ & \multirow[t]{2}{*}{ MG2 } & $0.686^{* *}$ \\
\hline & $(5.33)$ & & $(18.13)$ \\
\hline \multirow[t]{2}{*}{ G3 } & $0.134^{* *}$ & \multirow[t]{2}{*}{ MG3 } & $0.336^{* *}$ \\
\hline & $(3.22)$ & & $(18.82)$ \\
\hline \multirow[t]{2}{*}{ G4 } & $0.097^{* *}$ & \multirow[t]{2}{*}{ MG4 } & $0.178^{* *}$ \\
\hline & $(3.02)$ & & $(10.32)$ \\
\hline \multirow[t]{2}{*}{ G5 } & -0.004 & \multirow[t]{2}{*}{ MG5 } & $0.075^{* *}$ \\
\hline & $(-0.13)$ & & $(6.40)$ \\
\hline $\mathrm{R}^{2}$ & 0.14 & & 0.55 \\
\hline DW & 2.36 & & 2.50 \\
\hline $\mathrm{T}$ & 426 & & 426 \\
\hline AIC & 813 & & 544 \\
\hline
\end{tabular}

Notes: Asterisks, $* *$ indicates statistical significance at the $5 \%$ level or better, two-tailed test. 